\title{
A review of culture-dependent and molecular methods for detection of Salmonella in food safety
}

\author{
${ }^{1 * T h u n g, ~ T . Y ., ~}{ }^{1,2}$ Lee, E., ${ }^{3}$ Wai, G.Y., ${ }^{4}$ Pui, C.F., ${ }^{5}$ Kuan, C.H., ${ }^{6}$ Premarathne, J.M.K.J.K., \\ ${ }^{7}$ Nurzafirah, M., ${ }^{1}$ Tan, C.W., ${ }^{1}$ Malcolm, T.T.H., ${ }^{1}$ Ramzi, O.S.B., ${ }^{2}$ Wendy, D.R., ${ }^{1}$ New, C.Y. \\ and ${ }^{1,2}$ Son, $\mathrm{R}$. \\ ${ }^{1}$ Department of Food Science, Faculty of Food Safety and Technology, Universiti Putra Malaysia, 43400 \\ Serdang, Selangor, Malaysia \\ ${ }^{2}$ Food Safety and Food Integrity, Institute of Tropical Agriculture and Food Security, Universiti Putra \\ Malaysia, 43400 Serdang, Selangor, Malaysia \\ ${ }^{3}$ Faculty of Bioresources and Food Industry, Universiti Sultan Zainal Abdin, 22200 Kuala Besut, \\ Terengganu, Malaysia \\ ${ }^{4}$ Faculty of Resource Science and Technology, Universiti Malaysia Sarawak, 94300 Kota Samarahan, \\ Sarawak, Malaysia \\ ${ }^{5}$ Department of Agricultural and Food Science, Faculty of Science, Universiti Tunku Abdul Rahman, 31900 \\ Kampar, Perak, Malaysia \\ ${ }^{6}$ Department of Livestock and Avian Science, Faculty of Livestock, Fisheries and Nutrition, Wayamba \\ University of Sri Lanka, Makandara, 60170 Gonawila, Sri Lanka \\ ${ }^{7}$ Department of Diagnostic and Allied Science, Faculty of Health and Life Science, Management and \\ Science University, 40100 Shah Alam, Selangor, Malaysia
}

\author{
Article history: \\ Received: 30 January 2019 \\ Received in revised form: 23 \\ February 2019 \\ Accepted: 6 March 2019 \\ Available Online: 12 March \\ 2019
}

Keywords:

Salmonella,

Detection,

Food safety

\begin{abstract}
Salmonella is the well-recognized foodborne pathogen leading the most research and surveillance attention especially from government agencies as well as in food industry. In Malaysia, Salmonella is one of the main bacteria which monitored by the National Laboratory Surveillance System. Previously, standard culture methods have always been employed by many laboratories for Salmonella detection in Food Surveillance Programs. However, more advanced detection methods will be needed to improve the sensitivity and specificity of Salmonella identification. In this review, Salmonella detection methods including conventional and recent advances in molecular-based methods will be discussed.
\end{abstract}

DOI:

https://doi.org/10.26656/fr.2017.3(6).018

\section{Introduction}

Foodborne infectious disease caused by bacterial pathogens is a major health problem worldwide. Among the foodborne pathogens, Salmonella is the most common bacteria associated with outbreaks known as salmonellosis, and is contracted through consumption of contaminated animal products, which always results either from infected animals used in food production or from contamination of the carcasses (Cheung and Kam, 2012; Park et al., 2014). Based on surveillance studies, the main vehicles of Salmonella infection include raw meat, eggs and poultry products (de Freitas et al., 2010; Sallam et al., 2014). Of greater consequence is that fruits and vegetables have gained notoriety in recent years as vehicles of human salmonellosis (Mritunjay and Kumar, 2015). The prevailing hygienic conditions especially in tropical and subtropical countries during the production, harvesting and distribution of fresh and dehydrated fruits and vegetables do not always meet minimum standards and may facilitate product contamination. For example, Salmonella spp. and Salmonella enterica serotype Typhimurium were detected in sliced fruits, like papaya, mango, jackfruit, watermelon, sapodilla, honeydew and dragon fruit (Pui et al., 2011), and local salad known as ulam (e.g., selom, pegaga nyonya, kacang panjang and kacang botol) (Najwa et al., 2015).

Rapid and reliable detection methods such as standard culture methods coupled with molecular techniques are necessary to control the safety of food. Typically, rapid methods have become increasingly popular among food testing laboratories and some of them have been accepted by international authorities as 
standard methods after thorough evaluation and validation. Therefore, different aspects of Salmonella detection and identification methodologies will be discussed in this review article.

\section{Detection and enumeration of Salmonella}

Detection and enumeration of Salmonella in foods and on surfaces that come into contact with food are an important component for ensuring food safety. For instance, conventional detection methods which provide both qualitative and quantitative information are used to isolate and enumerate viable bacterial cells in foods (de Boer and Beumer, 1999). Recently, considerable efforts have been made to improve the detection of Salmonella in different food ingredients by employing molecular detection method (Cheung and Kam, 2012). Hence, microbiological analysis comprises methods for quantitative detection is often used by both government authorities and food companies to monitor the state of contamination as well as to detect emerging risks (Park et al., 2014).

\subsection{Conventional methods}

Conventional culture methods acquired good reputation as standard techniques due to their selectivity and sensitivity (Taskila et al., 2012). Moreover, conventional test methods are simple, very practical and easily adaptable. Based on the standard ISO 6579:2002, detection process was involved in four stages: (a) nonselective pre-enrichment, (b) selective enrichment, (c) plating on selective media, and (d) biochemical and serological tests.

Prior to the enrichment cultivation, Salmonella could be injured during handling procedures and/or food processing, such as freezing, refrigeration, irradiation, drying, thermal treatment, low water activity, acidity, and starvation (Gracias and McKillip, 2004; Shintani, 2006). Thus, the first-line recovery of injured cells needs to be performed in a non-selective pre-enrichment step during the initial analysis. Buffered peptone water (BPW) contains sodium chloride and phosphates for the purpose of ensuring buffering capacity and maintaining osmotic balance, respectively. Due to low amounts of the target bacterial cells present in mixed microbial population, BPW often used to increase it (Taskila et al., 2012). Since non-selective media contain peptones (main sources of nitrogen and carbon), it might support or enhance other microbes to grow. Therefore, variety selective enrichment broths such as selenite cystine broth (SC), tetrathionate broth (TT), Rappaport Vassiliadis soy broth (RVS) and others have been developed for Salmonella isolation purposes (Taskila et al., 2012). RVS was reported as the best selective enrichment broth for Salmonella cultivation where it contains high concentration of malachite green and magnesium chloride which could be used to inhibit the growth of other microbial (Schönenbrücher et al., 2008).

Selective agar media such as brilliant green (BG) agar, bismuth sulphite (BS) agar and xylose lysine desoxycholate (XLD) agar are commonly used to differentiate and to receive presumptive Salmonella colonies (Sallam et al., 2014). Previously, chromogenic media such as CHROMagar Salmonella, chromogenic Salmonella esterase (CSE) agar, and alpha-beta chromogenic medium (ABC medium) have been developed to improve the selectivity (Perry and Freydière, 2007). In another study, researchers found that several chromogenic plating media such as MillerMallinson agar (MM), AES Salmonella agar plate (ASAP) and oxoid Salmonella chromogen media (OSCM) did not show any detection problems for falsepositive results in contrast to BG, XLD and xylose lysine tergitol 4 (XLT4) agar (Schönenbrücher et al., 2008).

Preliminary identification of Salmonella is often performed by biochemical tests, which may include the negative urease reaction, $\mathrm{H}_{2} \mathrm{~S}$ production, fermentation of dulcitol and glucose (Mirmomeni et al., 2009), whereas confirmation of the Salmonella genus is determined by serological tests using somatic (O), flagellar $(\mathrm{H})$ and capsular (Vi) antigens and their corresponding antibodies (Sallam et al., 2014). For instance, identification via biochemically and serologically was reported on various Salmonella serovars such as Agona, Arizonae, Bardo, Cerro, Dublin, Hadar, Gallinarum, Kentucky, Paratyphi A, Enteritidis, Typhimurium, Heidelberg and Virginia (Moussa et al., 2012).

On the other hand, the most probable number (MPN) method is widely applied to enumerate low concentration of microorganisms with $<10-100 \mathrm{MPN} / \mathrm{g}$ (Malorny et al., 2008). It appears particularly interesting as it provides quantitative data, ideally for estimating the numbers of viable bacteria which are distributed randomly within the sample. For example, researchers had employed MPN method to enumerate $S$. enterica serovar Typhimurium and $S$. enterica serovar Typhi in sliced fruits with estimated quantity ranging from 0 to $19 \mathrm{MPN} / \mathrm{g}$ (Pui et al., 2011). Similarly, MPN method was used to determine the density of $S$. enterica serovar Enteritidis and $S$. enterica serovar Typhimurium concentration in retail beef (Thung et al., 2018) and chicken meat (Thung et al., 2016). Recently, Tan et al. (2019) have also described the use of MPN method in the enumeration of Salmonella spp. in raw beef from wet market and hypermarket. 


\subsection{Molecular detection methods}

The advent of nucleic acid-based technologies, which referred to as rapid method, has improved sensitivity and specificity for detecting foodborne Salmonella with enhanced analytical performance and testing efficiency (Cheung and Kam, 2012). Molecular techniques are able to detect the target pathogens until defining subtle genetic differences at the strain level although the pathogens present in complex biological environments (Park et al., 2014). Therefore, these rapid detection methods could be of high value to the food industry.

\subsubsection{Polymerase chain reaction (PCR)}

Since the 1990s, molecular-based PCR assays are commonly used for the detection of Salmonella pure isolates from different samples (Soumet et al., 1999; Abouzeed et al., 2000). For instance, PCR assays have been used to detect selected virulence or antibiotic resistance genes along with genus-, species-, and/or serotype-specific genes of Salmonella in poultry and poultry products (Maciorowski et al., 2000; Oliveira et al., 2002). PCR methods employ several primer pairs which specific to Salmonella spp. genes, resulting in high sensitivity for the detection of Salmonella (Table 1).

The essential for detecting low levels of Salmonella and the non-even distribution of the bacterial cells in the samples, an enrichment step is usually required prior to PCR assay. It has been proposed that the use of culture enrichment prior to PCR analysis serves the following purposes, (i) multiplication of the target bacterial cells to provide detectable concentrations, (ii) dilution of dead cells, (iii) dilution of PCR-inhibitory substances such as detergents, organic and inorganic chemicals, polysaccharides, fats and denatured proteins present in the sample matrix, and (iv) the possibility of isolating the target bacterial cells for complementary tests (Cheung and Kam, 2012). For instance, PCR assay failed to detect positive samples when no pre-enrichment step was carried out for the detection of Salmonella in raw poultry tissue samples of naturally contaminated (Myint et al., 2006), but Salmonella was successfully detected after the enrichment cultivation step. In another study, a PCR assay incorporated with several DNA extraction methods was used for Salmonella detection in poultry samples (Soumet et al., 1994). They found that the presence of Salmonella was detected using PCR associated with an enrichment cultivation step for $10 \mathrm{hrs}$. Besides, detection of Salmonella at different enrichment times in poultry dietary samples using PCR was also investigated by Maciorowski et al. (2000). Noteworthy, one of the major factors affecting the efficiency of PCR is depending on the quality of the target DNA. However, the presence of contaminated DNA had resulted in poor efficiency of the PCR (Wegener et al., 2003). Therefore, developments of other sample preparation methods based on the sample matrix type are indispensable to improve PCR detection.

\subsubsection{Multiplex PCR (mPCR)}

The mPCR is a simultaneous detection for multiple targets DNA sequence occurs within a single reaction. It has been widely used for simultaneous detection of different pathogens or virulence factors, as well as applied in nucleic acid diagnostics field, which includes gene deletion and mutation analysis (Xu et al., 2013).

Table 1. Sequences of oligonucleotide primers used for detection of Salmonella

\begin{tabular}{|c|c|c|c|c|}
\hline Target gene & Primer & Sequence $\left(5^{\prime}-3^{\prime}\right)$ & Size (bp) & Reference \\
\hline \multirow{2}{*}{ Random sequence } & ST11 & GCCAACCATTGCTAAATTGGCGCA & \multirow{2}{*}{429} & \multirow{2}{*}{ Soumet et al. (1999) } \\
\hline & ST15 & GGTAGAAATTCCCAGCGGGTACTGG & & \\
\hline \multirow{2}{*}{$f l i C$} & Fli15 & CGGTGTTGCCCAGGT TGGTAAT & \multirow{2}{*}{620} & \multirow{2}{*}{ Oliveira et al. (2002) } \\
\hline & Typ04 & ACTGGTAAAGATGGCT & & \\
\hline \multirow{2}{*}{$S d f I$} & ENTF & TGTGTTTTATCTGATGCAAGAGG & \multirow{2}{*}{304} & \multirow{2}{*}{ de Freitas et al. (2010) } \\
\hline & ENTR & TGAACTACGTTCGTTCTTCTGG & & \\
\hline \multirow{2}{*}{ Spy } & TyphF & TTGTTCACTTTTTACCCCTGAA & \multirow{2}{*}{401} & \multirow{2}{*}{ de Freitas et al. (2010) } \\
\hline & TyphR & CCCTGACAGCCGTTAGATATT & & \\
\hline \multirow{2}{*}{$\operatorname{ViaB}$} & ViaBF & CACGCACCATCATTTCACCG & \multirow{2}{*}{738} & \multirow{2}{*}{ de Freitas et al. (2010) } \\
\hline & ViaBR & AACAGGCTGTAGCGATTTAGG & & \\
\hline \multirow{2}{*}{ 23S rRNA } & Sty-1 & TGCCGGAAACGAATCT & \multirow{2}{*}{300} & \multirow{2}{*}{ Pui et al. (2011) } \\
\hline & Sty-2 & GGTTGTCATGCCAATGCACT & & \\
\hline \multirow{2}{*}{ floR } & floRF & GAGATCGGATTCAGCTTTGC & \multirow{2}{*}{198} & \multirow{2}{*}{ Deekshit et al. (2013) } \\
\hline & floRR & CGGTAGGATGAAGGTGAGGA & & \\
\hline \multirow{2}{*}{$\operatorname{inv} A$} & invAF & GTGAAATTATCGCCACGTTCGGGCAA & \multirow{2}{*}{284} & \multirow{2}{*}{ Deekshit et al. (2013) } \\
\hline & invAR & TCATCGCACCGTCAAAGGAACC & & \\
\hline \multirow{2}{*}{$\operatorname{ssaT}(\mathrm{SPI}-2)$} & ssaTF & ATGCGCAAATAATGGTTGAT & \multirow{2}{*}{780} & \multirow{2}{*}{ Deekshit et al. (2013) } \\
\hline & ssaTR & TCAGGCGCGTTAACAGGACG & & \\
\hline \multirow{2}{*}{$s p v C$} & $\mathrm{spvCF}$ & CGGAAATACCATCAAATA & \multirow{2}{*}{669} & \multirow{2}{*}{ Thung et al. (2018) } \\
\hline & spvCR & CCСАAАCСCAТАСТТАСТСТG & & \\
\hline \multirow{2}{*}{ ompC } & ompCF & ATCGCTGACTTATGCAATCG & \multirow{2}{*}{204} & \multirow{2}{*}{ Tan et al. (2019) } \\
\hline & ompCR & CGGGTTGCGTTATAGGTCTG & & \\
\hline
\end{tabular}


Also, mPCR was used for screening of single nucleotide polymorphism (SNP) (Hayden et al., 2008). High compatibility of the primers and the reaction mixture is of great significance for $\mathrm{mPCR}$, especially in the detection of Salmonella simultaneously with other pathogens in food samples. For example, four sets of specific primers were used in $\mathrm{mPCR}$ to detect Escherichia coli O157: H7, Salmonella spp., Staphylococcus aureus, and Listeria monocytogenes in kimchi products (Park et al., 2006). Similarly, the detection of Escherichia coli O157:H7, Listeria monocytogenes and Salmonella spp. in meat and meat products, Vibrio parahaemolyticus and Vibrio cholerae in seafood and seafood products, and Staphylococcus aureus in ready-to-eat foods was also performed by using six pairs of primers in the MPCR assay (Lei et al., 2008). On the other hand, mPCR assay appears to be a more reliable method for identification of specific Salmonella serotypes, as compared to other assays by using phenotypic serotyping methods. In the study of Moussa et al. (2012), mPCR was used for molecular typing of Salmonella enterica serovars, especially in detecting $S$. enterica serovar Enteritidis and S. enterica serovar Typhimurium. It has also been widely used for differentiation of the Enteritidis and Typhimurium serovars in meat samples by other researchers. For example, mPCR was successfully adapted to identify $S$. enterica serovar Enteritidis, S. enterica serovar Typhi and $S$. enterica serovar Typhimurium in chicken meat with the amplification of SdfI gene, ViaB gene and Spy gene, respectively (de Freitas et al., 2010). Meanwhile, Deekshit et al. (2013) had employed mPCR for the detection of pathogenicity island 2 (SPI-2) genes in Salmonella from seafood.

\section{Whole genome sequencing (WGS) of Salmonella}

To date, WGS technology is used to evaluate and identify new species based on the entire DNA sequence of a bacterium thereby making it as a good surveillance tool (Ricke et al., 2018). WGS can be used to characterize individual microbes which include the full complement of resistance determinants, providing definite genotype information (McDermott et al., 2016). For example, WGS (Illumina HiSeq 2000 high throughput sequencing system) was used to analyze $S$. enterica serovar Weltevreden strains which isolated from contaminated food samples and human stool, where antimicrobial resistance (AMR) genes linked to resistance to ampicillin, ciprofloxacin or tetracycline was identified (Li et al., 2018). Previously, Wang et al. (2017) performed a WGS (PacBioRS II system) study analyzing Salmonella Indiana strain D90 isolated from the chicken carcass in China. They found that 24 multidrug resistance (MDR) genes, located on 4 plasmids, were identified, including the $m c r-1$ gene related to colistin resistance. Concurrently, a WGS approach was used to study cefoxitin-resistant Salmonella enterica serovar Heidelberg isolates from retail poultry, abattoir poultry and humans (Edirmanasinghe et al., 2017). They found that transmission of a common antimicrobial resistance plasmid (CMY-2) which linked to microbial resistance against $\beta$-lactamic antibiotics might occur among Salmonella Heidelberg strains with different genetic backgrounds. While the application of WGS coupled with specific computer programs might improve the interpretation of the heterogeneity typically in Salmonella genome classification. For instance, a software program Panseq was developed for the analyses of genomes as well as to identify bacterial strain (species -, subspecies- and serovar) using a SuperPhy platform (Laing et al., 2017).

\section{Conflict of Interest}

The authors declare no conflict of interest.

\section{Acknowledgments}

Preparation of this review was funded by the Fundamental Research Grant Scheme (FRGS) from the Ministry of Higher Education (MOHE), Malaysia (01-01 -18-2015FR).

\section{References}

Abouzeed, Y.M., Hariharan, H., Poppe, C. and Kibenge, F.S.B. (2000). Characterization of Salmonella isolates from beef cattle, broiler chickens and human sources on Prince Edward Island. Comparative Immunology, Microbiology and Infectious Diseases, 23(4), 253-266. https://doi.org/10.1016/S0147-9571 (99)00079-X

Cheung, P.Y. and Kam, K.M. (2012). Salmonella in food surveillance: PCR, immunoassays, and other rapid detection and quantification methods. Food Research International, 45(2), 802-808. https:// doi.org/10.1016/j.foodres.2011.12.001

de Boer, E. and Beumer, R.R. (1999). Methodology for detection and typing of foodborne microorganisms. International Journal of Food Microbiology, 50(12), 119-130. https://doi.org/10.1016/S0168-1605(99) 00081-1

de Freitas, C.G., Santana, A.P., da Silva, P.H.C., Goncalves, V.S.P., Barros, M.A.F., Torres, F.A.G., Murata, L.S. and Perecmanis, S. (2010). PCR multiplex for detection of Salmonella Enteritidis, Typhi and Typhimurium and occurrence in poultry meat. International Journal of Food Microbiology, 139(1-2), 15-22. https://doi.org/10.1016/ 
j.ijfoodmicro.2010.02.007

Deekshit, V.K., Kumar, B.K., Rai, P., Rohit, A. and Karunasagar, I. (2013). Simultaneous detection of Salmonella pathogenicity island 2 and its antibiotic resistance genes from seafood. Journal of Microbiological Methods, 93(3), 233-238. https:// doi.org/10.1016/j.mimet.2013.03.015

Edirmanasinghe, R., Finley, R., Parmley, E.J., Avery, B.P., Carson, C., Bekal, S., Golding, G. and Mulvey, M.R. (2017). A whole-genome sequencing approach to study cefoxitin-resistant Salmonella enterica serovar Heidelberg isolates from various sources. Antimicrobial Agents and Chemotherapy, 61, e01919 -16. https://doi.org/10.1128/AAC.01919-16

Gracias, K.S. and McKillip, J.L. (2004). A review of conventional detection and enumeration methods for pathogenic bacteria in food. Canadian Journal of Microbiology, 50(11), 883-890. https:// doi.org/10.1139/w04-080

Hayden, M.J., Nguyen, T.M., Waterman, A. and Chalmers, K.J. (2008). Multiplex-ready PCR: A new method for multiplexed SSR and SNP genotyping. BMC Genomics, 9, 80. https://doi.org/10.1186/14712164-9-80

Laing, C.R., Whiteside, M.D. and Gannon, V.P.J. (2017). Pan-genome analyses of the species Salmonella enterica, and identification of genomic markers predictive for species, subspecies, and serovar. Frontiers in Microbiology, 8, 1345. https:// doi.org/10.3389/fmicb.2017.01345

Lei, I.F., Roffey, P., Blanchard, C. and Gu, K. (2008). Development of a multiplex PCR method for the detection of six common foodborne pathogens. Journal of Food and Drug Analysis, 16, 37-43.

Li, B., Yang, X., Tan, H., Ke, B., He, D., Wang, H., Chen, Q., Ke, C. and Zhang, Y. (2018). Whole genome sequencing analysis of Salmonella enterica serovar Weltevreden isolated from human stool and contaminated food samples collected from the Southern coastal area of China. International Journal of Food Microbiology, 266, 317-323. https:// doi.org/10.1016/j.ijfoodmicro.2017.10.032

Maciorowski, K.G., Pillai, S.D. and Ricke, S.C. (2000). Efficacy of a commercial polymerase chain reactionbased assay for detection of Salmonella spp. in animal feeds. Journal of Applied Microbiology, 89 (4), 710-718. https://doi.org/10.1046/j.13652672.2000.01171.x

Malorny, B., Löfström, C., Wagner, M., Krämer, N. and Hoorfar, J. (2008). Enumeration of Salmonella bacteria in food and feed samples by Real-Time PCR for quantitative microbial risk assessment. Applied and Environmental Microbiology, 74(9), 1299-1304. https://doi.org/10.1128/AEM.02489-07

McDermott, P.F., Tyson, G.H., Kabera, C., Chen, Y., Li, C., Folster, J.P., Ayers, S.L., Lam, C., Tate, H.P. and Zhao, S. (2016). Whole genome sequencing for detecting antimicrobial resistance in nontyphoidal Salmonella. Antimicrobial Agents and Chemotherapy, 60, 5515-5520. https:// doi.org/10.1128/AAC.01030-16

Mirmomeni, M.H., Naderi, S., Colagar, A.H. and Sisakhtnezhad, S. (2009). Isolation of Salmonella enteritidis using biochemical tests and diagnostic potential of SdfI amplified gene. Research Journal of Biological Sciences, 4, 656-661.

Moussa, I.M., Ashgan, M.H., Mahmoud, M.H. and AlDoss, A.A. (2012). Rapid detection and characterization of Salmonella enterica serovars by multiplex polymerase chain reaction assay. African Journal of Biotechnology, 11, 3452-3458. https:// doi.org/10.5897/AJB11.1353

Mritunjay, S.K. and Kumar, V. (2015). Fresh farm produce as a source of pathogens: a review. Research Journal of Environmental Toxicology, 9 (2), 59-70. https://doi.org/10.3923/rjet.2015.59.70

Myint, M.S., Johnson, Y.J., Tablante, N.L. and Heckert, R.A. (2006). The effect of pre-enrichment protocol on the sensitivity and specificity of PCR for detection of naturally contaminated Salmonella in raw poultry compared to conventional culture. Food Microbiology, 23(6), 599-604. https:// doi.org/10.1016/j.fm.2005.09.002

Najwa, M.S., Rukayadi, Y., Ubong, A., Loo, Y.Y., Chang, W.S., Lye, Y.L., Thung, T.Y., Aimi, S.A., Malcolm, T.T.H., Goh, S.G., Kuan, C.H., Yoshitsugu, N., Nishibuchi, M. and Son, R. (2015). Quantification and antibiotic susceptibility of Salmonella spp., Salmonella Enteritidis and Salmonella Typhimurium in raw vegetables (ulam). International Food Research Journal, 22, 17611769.

Oliveira, S.D., Santos, L.R., Schuch, D.M.T., Silva, A.B., Salle, C.T.P. and Canal, C.W. (2002). Detection and identification of salmonellas from poultry-related samples by PCR. Veterinary Microbiology, 87(1), 25-35. https://doi.org/10.1016/ S0378-1135(02)00028-7

Park, S.H., Aydin, M., Khatiwara, A., Dolan, M.C., Gilmore, D.F., Bouldin, J.L., Ahn, S. and Ricke, S.C. (2014). Current and emerging technologies for rapid detection and characterization of Salmonella in poultry and poultry products. Food Microbiology, $38, \quad 250-262 . \quad$ https://doi.org/10.1016/ j.fm.2013.10.002 
Park, Y.S., Lee, S.R. and Kim, Y.G. (2006). Detection of Escherichia coli O157:H7, Salmonella spp., Staphylococcus aureus and Listeria monocytogenes in kimchi by multiplex polymerase chain reaction (mPCR). The Journal of Microbiology, 44, 92-97.

Perry, J.D. and Freydière, A.M. (2007). The application of chromogenic media in clinical microbiology. Journal of Applied Microbiology, 103(6), 20462055. 2672.2007.03442.x

Pui, C.F., Wong, W.C., Chai, L.C., Nillian, E., Ghazali, F.M., Cheah, Y.K., Nakaguchi, Y., Nishibuchi, M. and Son, R. (2011). Simultaneous detection of Salmonella spp., Salmonella Typhi and Salmonella Typhimurium in sliced fruits using multiplex PCR. Food Control, 22(2), 337-342. https:// doi.org/10.1016/j.foodcont.2010.05.021

Ricke, S.C., Kim, S.A., Shi, Z. and Park, S.H. (2018). Molecular-based identification and detection of Salmonella in food production systems: current perspectives. Journal of Applied Microbiology, 125 (2), 313-327. https://doi.org/10.1111/jam.13888

Sallam, K.I., Mohammed, M.A., Hassan, M.A. and Tamura, T. (2014). Prevalence, molecular identification and antimicrobial resistance profile of Salmonella serovars isolated from retail beef products in Mansoura, Egypt. Food Control, 38, 209 -214. https://doi.org/10.1016/j.foodcont.2013.10.027

Schönenbrücher, V., Mallinson, E.T. and Bülte, M. (2008). A comparison of standard cultural methods for the detection of food-borne Salmonella species including three new chromogenic plating media. International Journal of Food Microbiology, 123(12), 61-66. j.ijfoodmicro.2007.11.064

Shintani, H. (2006). Importance of considering injured microorganisms in sterilization validation. Biocontrol Science, 11(3), 91-106. https:// doi.org/10.4265/bio.11.91

Soumet, C., Ermel, G., Rose, N., Rose, V., Drouin, P., Salvat, G. and Colin, P. (1999). Evaluation of a multiplex PCR assay for simultaneous identification of Salmonella sp., Salmonella Enteritidis and Salmonella Typhimurium from environmental swabs of poultry houses. Letters in Applied Microbiology, 28(2), 113-117. https://doi.org/10.1046/j.13652672.1999.00488.x

Soumet, C., Ermel, G., Fach, P. and Colin, P. (1994). Evaluation of different DNA extraction procedures for the detection of Salmonella from chicken products by polymerase chain reaction. Letters in Applied Microbiology, 19(5), 294-298. https:// doi.org/10.1111/j.1472-765X.1994.tb00458.x
Tan, C.W., Noor Hazirah, M.Z., Shu'aibu, I., New, C.Y., Malcolm, T.T.H., Thung, T.Y., Lee, E., Wendy, R.D., Nuzul, N.J., Noor Azira, A.M., Ungku Fatimah, U.Z.A., Rukayadi, Y., Rinai, R. and Son, R. (2019). Occurrence and antibiotic resistance of Salmonella spp. in raw beef from wet market and hypermarket in Malaysia. Food Research, 3(1), 2127. https://doi.org/10.26656/fr.2017.3(1).202

Taskila, S., Tuomola, M. and Ojamo, H. (2012). Enrichment cultivation in detection of food-borne Salmonella. Food Control, 26(2), 369-377. https:// doi.org/10.1016/j.foodcont.2012.01.043

Thung, T.Y., Mahyudin, N.A., Basri, D.F., Wan Mohamed Radzi, C.W.J., Nakaguchi, Y., Nishibuchi, M. and Son, R. (2016). Prevalence and antibiotic resistance of Salmonella Enteritidis and Salmonella Typhimurium in raw chicken meat at retail markets in Malaysia. Poultry Science, 95(8), 1888-1893. https://doi.org/10.3382/ps/pew144

Thung, T.Y., Son, R., Mahyudin, N.A., Rukayadi, Y., Zakaria, Z., Mazlan, N., Tan, B.H., Lee, E., Yeoh, S.L., Chin, Y.Z., Tan, C.W., Kuan, C.H., Basri, D.F. and Wan Mohamed Radzi, C.W.J. (2018). Prevalence, virulence genes and antimicrobial resistance profiles of Salmonella serovars from retail beef in Selangor, Malaysia. Frontiers in Microbiology, 8, 2697. https://doi.org/10.3389/ fmicb.2017.02697

Wang, J., Li, X., Li, J., Hurley, D., Bai, X., Yu, Z., Cao, Y., Wall, E., Fanning, S. and Bai, L. (2017). Complete genetic analysis of a Salmonella enterica serovar Indiana isolate accompanying four plasmids carrying $m c r-1$, ESBL and other resistance genes in China. Veterinary Microbiology, 210, 142-146. https://doi.org/10.1016/j.vetmic.2017.08.024

Wegener, H.C., Hald, T., Wong, D.L.F., Madsen, M., Korsgaard, H., Bager, F., Gerner-Smidt, P. and Mølbak, K. (2003). Salmonella control programs in Denmark. Emerging Infectious Diseases, 9, 774-780. https://doi.org/10.3201/eid0907.030024

$\mathrm{Xu}, \mathrm{Z}$., Chen, W., Merke, D.P. and McDonnell, N.B. (2013). Comprehensive mutation analysis of the CYP21A2 gene: An efficient multistep approach to the molecular diagnosis of congenital adrenal hyperplasia. The Journal of Molecular Diagnostics, 15(6), 745-753. https://doi.org/10.1016/ j.jmoldx.2013.06.001 